https://doi.org/10.26754/ojs_aem/aem.2017282081

Recibido: $15 / 10 / 17$

Aragón en la Edad Media

Aceptado: 21/12/17

28 (2017) $15-38$

e-ISSN: 2387-1377

ISSN: 0213-2486

\title{
PATRIMONIO HISTÓRICO. EL AZAFRÁN MEDIEVAL DE GÚDAR-MAESTRAZGO
}

HISTORIC HERITAGE. THE MEDIEVAL SAFFRON OF GÚDAR-MAESTRAZGO

\author{
Joaquín ApArICI MARTí \\ Universitat Jaume I. Castelló
}

\begin{abstract}
Resumen: Producto de escasa entidad física, pero alto valor económico, el azafrán cultivado en determinadas zonas de la Corona de Aragón durante la Edad Media permitió establecer circuitos de intercambio a nivel internacional. Presentamos ahora una de esas zonas de producción.
\end{abstract}

Palabras clave: patrimonio, azafrán, Edad Media, Corona de Aragón.

\begin{abstract}
Product of scarce physical entity, but high economic value, the saffron produced in certain areas of the Crown of Aragon during the Middle Ages allowed to stablish circuits of interchange at international level. Now we present one of those areas of production.
\end{abstract}

Key words: heritage, saffron, Middle Ages, Crown of Aragon. 


\section{El producto ${ }^{1}$}

Especia de uso culinario, históricamente el azafrán ha servido a su vez como elemento en farmacopea, como ingrediente en perfumes o como colorante natural. De laboriosa recolección y preparación, la productividad, que no la producción, puede justificar la denominación de la especia como «oro rojo», así como también fundamentar el elevado precio final del mismo. De la misma manera, permite demostrar a su vez la existencia de toda una picaresca a su alrededor que, mediante la adulteración del producto, trata de aumentar todavía más si cabe el beneficio obtenido en su comercialización.

El azafrán comercializado es el conjunto de estigmas, desecados o en polvo, obtenidos de la flor que produce la propia planta del azafrán. Nacida de un bulbo, en el extremo superior del tallo encontramos las flores que poseen pétalos de color violáceo, tres estigmas de color escarlata (los briznes), así como estambres de color amarillento. Son los estigmas los que se usan para la obtención del azafrán, mientras que los estambres formarían un subproducto sin valor comercial pero que, en ocasiones, podía ser utilizado para la adulteración. La planta como tal acepta una enorme variedad de condiciones ecológicas, tanto edáficas (suelos), como climáticas, si bien preferentemente se sitúa su cultivo en climas templados continentales, o mediterráneo de transición continental, con inviernos frescos y veranos calurosos y secos, y con precipitaciones no muy abundantes a lo largo del año, emplazando el área de cultivo en unas altitudes entre 600 y 1200 metros (Rubio, 2007: 202-203). Posiblemente, estas circunstancias geo-climáticas pueden explicar la importancia alcanzada por este producto como cultivo durante la Edad Media en ciertas zonas interiores de Cataluña y de Teruel.

La cebolla del azafrán se planta a fines de junio, en surcos con una profundidad de 20 centímetros que la protegerá de las inclemencias climáticas. Durante el otoño se produce la floración del azafrán, en un lapso de 15 a 25 días, entre mediados de octubre y noviembre. Cada día nacen nuevas flores que son recogidas manualmente durante las primeras horas para evitar que la insola-

1 El presente trabajo se enmarca en el contexto de una estancia de investigación realizada en el Departamento de Historia Medieval, Ciencias y Técnicas Historiográficas y Estudios Árabes e Islámicos de la Universidad de Zaragoza, para un período de dos meses (del 15 de julio al 15 de septiembre de 2017), bajo la temática de las conexiones económicas, sociales y culturales entre el sur de Aragón y las tierras de Castellón, incidiendo especialmente en la puesta en valor del patrimonio cultural y documental de la zona de Gúdar-Maestrazgo. 
ción las marchite. Generalmente es la segunda semana de floración la que ofrece un mayor volumen de producto, menguando progresivamente a partir de ese momento. Recogidas en cestos de mimbre, las flores se extienden en casa para su aireado y posteriormente se procede al desbriznado (obtención de los estigmas) procurando no romperlos y que mantengan el color rojizo, sin tonos amarillentos (de los estambres) ni violáceos (de los pétalos). En esta labor la intensidad del trabajo es importante, reuniéndose generalmente los miembros de la familia para poder aumentar la productividad, puesto que para obtener un quilogramo de azafrán seco se precisa de la manipulación de unas 100.000 flores aproximadamente. Pero el proceso continúa con el tueste a fuego lento de los briznes, formando con éstos una especie de torta de entre 0,5 y 1 centímetro de grosor, para conseguir la eliminación del agua que contienen, labor compleja puesto que un exceso de tueste restaría valor al producto, y una deshidratación incorrecta podría provocar la putrefacción del mismo. Finalizado el proceso, el azafrán resultante se almacena protegido de la luz, de la humedad y del aire, para conservar así el aroma y el color hasta que se produzca su posterior comercialización (Rubio, 1997: 55-74 y 2007: 205).

\section{El azafrán en los territorios peninsulares de la Corona de Aragón}

Sobre el valor medieval del azafrán, se pueden argumentar varias ventajas en su cultivo (Verdés, 2008: 227-228). La primera es que podía funcionar como «producto ahorro» pues, tras el desecado, su conservación quedaba asegurada durante un lapso de tiempo que podía durar varios años, aspecto que, unido a su elevado valor económico con respecto a su escasa entidad material, lo convertían en un elemento para cubrir gastos en cualquier momento inesperado. Una segunda ventaja es que, a pesar de la necesidad de mano de obra, el rendimiento es muy elevado y podía incluso aumentar si se lograban reducir los costes de la explotación circunscribiendo su cultivo al potencial de trabajo que poseía cada unidad familiar. Una tercera ventaja era su perfecta adaptación al policultivo medieval, puesto que el principal esfuerzo en la cosecha del azafrán (octubre a noviembre) no interfería en gran medida en el resto de actividades agrarias, además de que el azafrán proporcionaba un rendimiento casi inmediato y que, en caso necesario, rápidamente la parcela cultivada podía reconvertirse en campo de cereales. Finalmente, no podemos olvidar la demanda comercial del producto, que lo hacía atractivo gracias a su elevado 
precio. Por ello, a la especialización agraria en su producción en determinadas regiones italianas e hispánicas se unió su comercialización hacia los mercados del norte de Europa que demandaban dicho producto (Petino, 1951).

En los diversos territorios peninsulares que conforman la Corona de Aragón se desarrolla el cultivo del azafrán durante la Edad Media. Desde inicios del siglo XIV se documenta en tierras catalanas la producción y exportación de azafrán hacia las ferias de Champagne y la región de Flandes. Por ejemplo, desde Manresa entre 1334 y 1356 se documentan más de un centenar de viajes hacia dichos destinos, con importantes cantidades de este producto que, en su global, ascienden a la nada desdeñable cantidad de 5 toneladas y 178 quilogramos (Rafat, 1993: 270-279). Por las mismas fechas, lugares como Cardona muestran también una importante producción y almacenamiento. Se une además la consideración social del «valor» del producto pues diversas mandas testamentarias son sufragadas, por orden del testador, con el valor que alcanza el azafrán (Galera, 2015: 540). Con todo, parece ser que es la primera mitad del siglo xv la que marca el momento de máximo auge, con un gran protagonismo del producto autóctono en ámbito europeo, y con la atracción suscitada sobre el interés de los comerciantes alemanes (Diago, 2002). De hecho, la importancia del azafrán catalán es tal que hubo que tomar disposiciones para evitar el fraude, tanto en el proceso de secado como en su posterior comercialización, con órdenes y constituciones reales que se datan en 1353, o con la legislación emanada desde la diputación, institución que en 1442 reúne a personas expertas en el comercio del azafrán para tratar de nuevo las ordenanzas emitidas sobre su elaboración y comercialización, pues éstas habían provocado ciertas protestas. De hecho, las ordenanzas enviadas por la diputación a las autoridades locales muestran un gran interés por el control total sobre el circuito que sigue el azafrán, con la reglamentación sobre su producción y elaboración castigando el fraude, la regulación estricta de su comercialización, la creación de un personal cualificado capaz de asegurar el cumplimiento de la normativa (veedor del safrà), y por último, la organización de una fiscalidad que grave la exportación de tan preciado producto (dret d'eixida del safrà). A fines del siglo XIV, poblaciones como Cardona, Vilafranca del Penedés, Igualada, Cervera, Tárrega o Balaguer forman parte de la ruta del azafrán camino a Barcelona (Galera, 2015: 542). En 1441 sigue manteniéndose el listado como tal, ampliándose con Montblanc, Guissona, Santa Coloma de Queralt o Calaf entre otras, como principales núcleos de producción y comercialización del azafrán (Verdés, 2001). 
Ese azafrán se encaminó inicialmente hacia la ciudad de Barcelona que se convirtió en importante puerto de distribución del producto ya a fines del siglo XIV. Para ese período se documentan hasta 8 contratos que hacen referencia directa a la exportación del azafrán con destino a Flandes (Polonio, 2012: 380383). ${ }^{2}$ Además, el azafrán y su comercio por parte de mercaderes de las compañías alemanas (Diago, 2002) es actualmente objeto de investigación utilizando como fuente documental las series conservadas relativas al derecho alemán y saboyano entre 1425 y 1445 (Casado, 2014 y 2014-2015). El listado del derecho real sobre el comercio de los alemanes, datado en 1443 y conservado en Barcelona, muestra a varios mercaderes alemanes (Jous Hompis, Johan de Colunya, Gaspar de Vat, o Jaume Rostenegater de Ulm) importando productos textiles, como lienzos de Suavia, fustanes, telas y cañamazos de los Países Bajos, así como también metal. Mientras, en el lado de las exportaciones destacaba especialmente el azafrán. ${ }^{3}$ Como ejemplo, el 26 de enero Mateu Stany y Joan de Colunya declaran sacar 300 libras de safrà contrafet d'Orta y otras 240 libras de safrà d'Orta. El mismo día, Jous Hompis declara sacar otras 900 libras de safrà d'Orta y 440 libras de safrà contrafet. También se menciona la variante de safrà d'oli mercader (Schulte, 1923: 513-515). No sólo hay diversas variantes de azafrán comercializado ${ }^{4}$ sino que además, en los ítems documentados, en ocasiones se indica que el producto sale por tierra (como el 1 de marzo) o en naves italianas como las galeras florentinas (el 26 de abril). Y respectivamente, la vía terrestre se dirige hacia Perpiñán y la vía marítima hacia Génova.

Ahora bien, la pujanza del comercio internacional del azafrán catalán parece entra en cierto declive como consecuencia de la guerra civil que sufre aquel

2 Cuadro núm. 71. Así, por ejemplo, el 13 de abril de 1394 documenta dos contratos por valor de, el primero 112 libras, y el segundo 104 libras 11 sueldos 1 dinero, que suponían respectivamente 95 libras y 6 onzas y media de azafrán balaguer, y 106 libras y 5 onzas de azafrán lestat. Un día después, el 14 de abril, documenta otros 5 contratos también con destino a Flandes. El último contrato que documenta sigue la ruta Sevilla, Cádiz, Flandes, y lleva azafrán y jengibre, datado el 10 de noviembre de 1428.

3 Los protagonistas se repiten en los listados de la lezda barcelonesa de 1434, con Johan de Colunya, Jos Hompis y Gaspar de Vat, mercaderes alemanes que se inclinaron preferentemente por la exportación de azafrán peninsular (Salicrú, 1995: 181).

4 Algunas de las variedades mencionadas en la documentación medieval catalana son: Orta, variedad de alta calidad muy demandada, que se tostaba con grasa de cerdo. Lestat, variedad que se caracterizaba por ser un azafrán sin impurezas, pero de calidad media. Balaguer, nombre bajo el que se reconocía el azafrán producido en la Cataluña central. Mercader, variedad considerada de calidad inferior. Contrafet, producto considerado azafrán adulterado. Oli, variedad que posiblemente se tostaba con aceite (Casado, 2014-2015: 588). 
territorio (1462-1472), y que pudo propiciar el desplazamiento de los centros de comercio del azafrán hacia tierras aragonesas y valencianas (Verdés, 2001: 759). Con todo, en ambos territorios ya se documenta el cultivo y comercio de dicho producto con anterioridad al citado momento bélico.

Los mismos mercaderes alemanes que actúan en Cataluña se interesan también por el azafrán aragonés, en una dinámica similar de exportación como pone de manifiesto el registro zaragozano de 1430. En este documento, los 57 ítems que muestran la salida de mercancías desde Zaragoza hacen referencia exclusiva al azafrán, si bien en algunos de los ítems el declarante indica que compró el producto en Cataluña, hacia donde es remitido para que abone el impuesto. Por ejemplo, en diciembre, Jous Hompis manifestà que havia comprat en Cathalunya 195 libras de azafrán, y que fonch remés a Barcelona per pagar lo dret (Schulte, 1923: 507-510). De la misma manera, las tablas de recaudación de la «collida» de Huesca muestran esa exportación. Dicha «collida» cubría la frontera con el territorio catalán al norte del río Ebro y percibía las tasas del tráfico de las rutas terrestres de esa zona hacia la ciudad de Barcelona, así como también la vía fluvial del Cinca y el Mequinenza, ya sobre el Ebro, en ruta hacia Tortosa. En Huesca se han conservado algunos registros, y en ellos se hace referencia al azafrán. Para el período comprendido entre agosto de 1449 y agosto de 1450 se muestran 1050 asientos de salidas, de los que 106 hacen referencia al azafrán, así como otros 51 de los 305 asientos de salidas de la tabla fragmentada e incompleta del período que ocupa desde junio a agosto del año 1447 (Sesma, 2005). En el primer caso, el volumen de azafrán consignado a su paso por la tabla ascendía a poco más de 296 libras, mientras que, en el segundo, el global alcanzaba algo más de las 96 libras y 7 onzas.

En el ámbito turolense también se documenta la producción del azafrán. ${ }^{5}$ Muniesa, un lugar del común de Huesa, ubicado en un ámbito geográfico privilegiado por encontrarse en el centro de un triángulo natural que une la zona de Daroca con Teruel y Zaragoza, la documentación notarial pone de manifiesto la importancia económica de su cultivo. De 1442 data una ordenanza en la que se penaliza con 2 sueldos el arriendo de tierras a forasteros que pretendan plantar azafrán. A fines de siglo, se prohíbe incluso la venta de la cebolla a los foráneos, es decir, a aquellos que no son del común de Huesa. Incluso se crea una tabla de control de las salidas del azafrán, siendo controlada en 1478 
por Luis de Rodiella, quien precisamente era uno de los principales mayoristas del comercio del azafrán (Martínez, 2012: 322-324). Pero, además, en dicha zona se documenta a mercaderes catalanes contratando la compra del azafrán a la colectividad de vecinos de Muniesa, al menos hasta 1460, momento en que serán sustituidos por mercaderes aragoneses, aunque el ciclo del azafrán seguía manteniendo el camino de exportación hacia tierras catalanas. Incluso en 1498 se documenta a dos mercaderes de origen alemán, Luís y Gaspar Solicofer, comprando azafrán en Muniesa y Daroca.

Otro de los territorios de la Corona de Aragón que participa en la producción y comercio de este producto es el reino de Valencia, ya desde inicios del siglo XIV. Así, algunas comandas mercantiles registradas en protocolos notariales durante la primera mitad de dicha centuria muestran una cierta variedad de productos agrícolas valencianos de consumo selecto o de dedicación industrial que son exportados hacia otros territorios. Entre dichos productos se documenta el azafrán, con destino hacia Túnez (1 comanda), las islas de Cerdeña (1 comanda) y Mallorca (1 comanda), o Andalucía (1 comanda). Así, por ejemplo, en 1326, los mercaderes Guillem Magencosa y Miquel Tolsá se reconocen mutuamente llevar en comanda diversos artículos, entre los que estaba el azafrán, en dos naves que van a realizar una travesía desde la costa valenciana a Sevilla (Mira, 2005).

En el transcurso del siglo xv se documenta el cultivo del azafrán en ámbitos geográficos valencianos diversos, tanto al sur como al norte del reino. En junio de 1422 Francesc Barceló expide hacia Nápoles en el ballenero de Bertolí Joan, de Denia, 10 libras de azafrán valenciano para el rey, a precio de 33 sueldos por libra. También la zona entorno a Elda produce alazor, variante del azafrán (safrà boit) a fines del siglo Xv. En 1496 los alemanes de la pequeña compañía compraron un global de 210 arrobas de este producto (Guiral, 1989: 420-422). ${ }^{6}$ Mientras, al norte, en 1498 se documenta el cultivo de azafrán en una población próxima a tierras turolenses, Caudiel, en la tenencia de Jérica. ${ }^{7}$

El azafrán valenciano es, al igual que el aragonés y catalán, objeto de exportación en ámbito europeo. En octubre de 1440 el mercader veneciano Nicolau Vener exporta un total de 39 arrobas de alaffor (azafrán bastardo), esti-

6 Joan Roís de Corella, conde de Cocentaina y Alí Almoací, de Elda, vendieron a Conrat Ancarita y a su factor Jous Vizlant, representante de la «chica companya», 60 y 150 arrobas respectivamente, de alazor. Se data el 4 de julio y el 8 de noviembre de 1496.

7 Archivo de la Catedral de Segorbe (ACS), protocolo 718 / 7 (1498, junio 8). 
madas en 48 libras (López, 1975). En 1446, Johan Lorenço, un marinero portugués de la villa de Viana, en calidad de procurador de Mair del Porto, judío portugués, reconoce que Joan Solanes, mercader de Valencia, le ha pagado 7 libras 12 sueldos 6 dineros restantes a pagar por 9 libras y 10 onzas de azafrán. ${ }^{8}$ En 1451, el mercader florentino residente en Valencia Bonjohan Johan Fillaci, por él mismo y por su sociedad, junto a Lorenç Soler y Pere Pardo, asegura con 100 libras por cada uno, a Rafael de Bellpuig, sobre 4 piezas de paños de lana en una bala y otros productos entre los que se documenta una caja grande con 27 libras de azafrán, cargados en la playa de Valencia en la galeata patroneada por un tal Gallardet, francés, navegando hacia Berbería o la España musulmana, descargando, cargando, y regresando a Valencia. ${ }^{9}$

Con todo, el azafrán valenciano también es exportado vía terrestre. En los registros de declaración de mercancías de salida por la aduana de Segorbe, para el amplio período que ocupa desde 1463 hasta 1490, el azafrán suma un modesto total de 11 libras y media más 69 onzas y media que salen de territorio valenciano hacia tierras aragonesas. Como vemos, cantidad casi anecdótica, pero presente (Villanueva, 2007: 204). Y en la Plana de Castelló documentamos su uso como colorante en 1394, cuando se pagaba cierta cantidad de dinero por el azafrán comprado por el consejo municipal de Vila-real para acolorar les dites diademes de los apóstoles que se hacían para la representación teatral del viernes santo. ${ }^{10}$

\section{La zona Gúdar-Maestrazgo. Regesta documental}

Ahora, la pretensión es dar a conocer otro ámbito geográfico productivo del azafrán, como son las tierras de confluencia entre la Sierra de Gúdar y el Maestrazgo, en sus dos vertientes, la aragonesa y la valenciana. La zona, con una altitud media por encima de los 1000 metros, con un clima mediterráneo continentalizado y una gradación forestal según nivel de altura, presenta en su conjunto las características necesarias que permiten el cultivo del azafrán. La zona aparece tradicionalmente vinculada a la explotación ganadera y a un hábitat en ocasiones disperso para aprovechar al máximo los posibles rendimientos del terrazgo, documentándose numerosas masías por los términos de

8 Archivo del Real Colegio Seminario del Corpus Christi de Valencia (APPV), prot. 25971 (1446, abril 9).

9 APPV, prot. 25975 (1451, septiembre 1).

10 Arxiu Municipal de Vila-real, Claveria 225, f. 49r. 
las poblaciones allí situadas (en la zona de Teruel núcleos como Cantavieja, La Iglesuela, Mirambel o La Cuba, y en zona castellonense núcleos como La Mata, Vilafranca, Olocau o Cinctorres). Las relaciones sociales, humanas y económicas entre los habitantes de esa zona de confluencia son constantes a lo largo de la edad media (Navarro y Aparici 2008; Aparici, 2010). En dicho ámbito geográfico documentamos, a nivel agrario, la presencia de parcelas (sorts, tros, banqual, terra) sin mayor especificación que la indicación que son de tierra, aunque en ocasiones se relaciona con el cultivo cerealístico (definidos en la documentación con sustantivos como tric, avenes, speltes, forment). También se hace mención a otras parcelas con ferreginals, viñas y parrales, huertos, carrascales, etc. Pero además ese territorio también fue, durante los siglos XIV y XV, zona de producción de azafrán, tanto en las estribaciones de la vertiente turolense como en la castellonense. La pista inicial nos la ofrece el consejo municipal de Mirambel cuando consigna, entre sus gastos, pagos efectuados con azafrán, que en 1475-1476 suponen un montante de 46 sueldos 5 dineros, pero que en el bienio 1488-1489 asciende ya a los 444 sueldos 2 dineros (Navarro, 2008: 43-45).

Partiendo de esa base, hemos iniciado una serie de búsquedas en la documentación conservada en el Archivo Notarial de Morella ${ }^{11}$ que ha reportado los datos que comentamos a continuación (un total de 76 documentos cuyo regesto y numeración se pueden consultar más abajo). Básicamente, el conjunto de noticias nos informan de la compra-venta anticipada del azafrán, obligándose el vendedor a entregarlo ya recogido, en alguna fase de elaboración (separación de estambres o en bri, ya seco o sech, documentos 1, 23, 34, $35,37,42,43,46,57)$ aunque lo normal es que se establece la compra anticipada respecto del global de la cosecha que se espera obtener en relación con una determinada superficie de tierra (cahizada, suerte, bancal), por lo que la cantidad final de producto queda supeditada a las posibles variaciones en dicha cosecha (doc. 24, 26). En ocasiones se especifica que se trata de la cabeza o cebolla plantada del azafrán, cabota o caboça de safrà (doc. 15, 25, 47, 48, $59,67,73)$. También en ese sentido se documentan contratos de venta anticipada del azafrán plantado, pero en porciones de tierra que no pertenecen al

11 A partir de ahora, ANM. De entre los más de 300 protocolos del período medieval existentes, los consultados han sido los siguientes (notario y signatura): Martí Gossa, 63, 64, 65. Antoni Esquerdo, 68, 69, 71, 73. Pere Çavall el mayor, 115, 120, 121, 122, 124, 125. Luís de la Guerola, 150. Jaume Perpinyà, 159, 160, 161, 162, 165. Pere Çavall el menor, 186, 187, 196 197, 198. Domènech Gorch, 242, 243 244, 245,246, 247. Gabriel Tàrrega, 249. Pere Aguilar, 265, 266. 
vendedor, quien especifica que el azafrán es suyo pero que aquel está en una parcela de otro propietario (doc. 11, 27, 30, 32, 33, 36, 38, 54, 60).

$\mathrm{Su}$ cultivo se circunscribe a una serie de poblaciones limítrofes, ubicadas unas en ámbito turolense y otras en ámbito castellonense, pero vecinas, al fin y al cabo. De un lado encontramos numerosas menciones al azafrán plantado en La Mata, aldea de Morella (doc. 2, 27, 41, 54, 55, 56, 62, 63), en Vilafranca (doc. 3, 4, 6, 8), Olocau (doc. 7, 27, 68), Cinctorres (9, 28, 40, 45, 53), La Todolella (60), El Portell de Morella (65), la masía de Celumbres $(14,29)$ o Saranyana (61). Las menciones en ámbito turolense son algo menores, a saber, La Cuba (11, 17, 73), Cantavieja (56), Mirambel (12, 58) o La Iglesuela (69). Aún así, podemos observar esa dualidad geográfica a su vez a través de la vecindad del comprador y vendedor establecida en el contrato (doc. 24, 42, $47,62,64,65,67,69)$ y que amplía la geografía hacia poblaciones como Fortanete, Cantavieja o Mosqueruela. Cabe unir también que la documentación permite en ocasiones hipotetizar sobre la posible existencia de ciertas zonas del término municipal que aglutinaron, en un espacio próximo, las parcelas de cultivo de azafrán, pues los lindes mencionados así lo indican (doc. 12). Sin embargo, la documentación disponible no nos permite observar que el cultivo del azafrán tuviera un peso específico o destacado en la zona, o en alguno de los términos municipales. Posiblemente su cultivo respondiera a un interés de diversificación agraria para la obtención de un mayor rendimiento económico del terrazgo debido al valor del producto. Las noticias, puntuales, sólo permiten ver la difusión capilar de su cultivo en una amplia zona interior que muestra parcelas en diversos núcleos habitados, pero poco más. Por ello, no es extraño observar como una misma parcela de tierra o sort aglutina cultivos de viña, tierra o sementera de cereal al mismo tiempo que el azafrán, como por ejemplo un troç de terra e safrà tot ensemps (doc. 45, 54, 55, 56, 58, 62).

Por otro lado, la importancia del azafrán y de su valor económico se puede observar en alguno de los documentos que muestra dicho producto como garantía de pago en determinadas operaciones efectuadas ante notario (doc. 11, 61), o que tiene un importante componente social según se muestra en determinados legados testamentarios o en la partición de bienes de un difunto entre sus herederos, consignándose en numerosas ocasiones que el azafrán restará común hasta el momento de su partición (doc. 3, 48, 49, 50, 51, 52, 58).

También cabe indicar que algunos de los participantes en este comercio de compra-venta reiteran su presencia en esta actividad, bien como propietarios del azafrán plantado en el parcelario y vendiéndolo de forma anticipada como Do- 
mingo Carbó en 1415 y 1420 (doc. 10, 22, 26), bien con menciones a la propiedad del parcelario, caso de Miquel Carbó en 1439 y 1444 (doc. 48, 56), o bien como compradores que, a través del azafrán, diversifican sus posibles inversiones, como Ramón d'Alp que compra el azafrán de varias parcelas en 1420 y 1427 (doc. 27, 38). O también una combinación de ambos, como el habitante de La Cuba Pere Batle, propietario de parcelas con azafrán en Mirambel que vende en 1416 (doc. 12) y posteriormente comprador del producto en 1429 y 1438 (doc. 42, 47). También podemos mencionar la posible actividad especulativa del vecino de Cinctorres Arnau Agulló, quien en agosto de 1421 compró el azafrán plantado en la tierra de Domingo Calbo, en la Torre de Navalles, por 22 sueldos 7 dineros, y en octubre de ese año vendía el azafrán plantado en dicha tierra por 41 sueldos, casi duplicando su inversión (doc. 30, 32). Sin embargo, en ninguno de estos casos, ni su actividad resulta estable a lo largo de los años, ni tampoco hemos podido observar la conexión de esa producción y comercio local con los mercaderes foráneos, ni tampoco atisbar el destino hacia el que se dirigía el azafrán de la zona, bien Aragón o bien Cataluña. Sólo en una ocasión hemos documentado a un comprador que procede de la zona de la Plana de Castelló, de la localidad de Nules (doc. 59), y que paradójicamente, según otros documentos, estaba en la zona comprando animales de tiro.

Finalmente, sólo uno de los documentos (50) nos permite seguir también, aunque sólo en parte, los trabajos relacionados para la obtención-preparación del azafrán, pues se menciona el rasclar, los raedós, despues el esbrinar así como la colocación o disposición del producto antes de su venta como azafrán seco. ${ }^{12}$

\section{Regestas documentales}

01/ 1392, septiembre 19 (ANM, prot. 63). Domingo Gorch vecino de La Mata confiesa haber recibido de Martí Escoriola, de La Mata, 66 sueldos en señal y paga de 4 libras de safrà sech que le ha vendido, producto que le entregará en fiesta de Todos Santos.

02/ 1392, septiembre 22 (ANM, prot. 63). Miquel Pastor, vecino de La Mata vende a Guiamó Roselló un safranar sito en el Coscollar, lo qual és en la mia eretat, precio de 300 sueldos, de los que Guiamó reconoce adeudar 215 sueldos.

12 Consúltese el proceso de preparación de la tierra, así como de la recogida y desbriznado, proceso descrito mes a mes en varias tablas (Rubio, 2007: 203-206). 
03/ 1392, noviembre 27 (ANM, prot. 68). En la partición de los bienes del difunto Pere Coloma, de Vilafranca, entre su viuda Valera de Collados, y el hijo de ambos Pere Coloma junto a su esposa Lucia, se reparten los bienes muebles de casa, ovejas y cabras, varias parcelas de tierra y una casa. Queda en común la sementera que hay en la era, un pajar, la era, útiles de cocina y pesos que hay en un patio, así como ítem, romanen los saffranars e los safrans comuns, en axí que de continent que serà cullit, se haie a partir.

04/ 1394, marzo 29 (ANM, prot. 69). Sancho Catalá, vecino de Vilafranca, confiesa deber a Andreu Navarro 106 sueldos precio de cuiusdam safranaris que le vendió, sitos en una masada en término de Vilafranca, al lado del boalar del carnicero, a pagar a Todos Santos.

05/ 1395, octubre 17 (ANM, prot. 71). Pere Coll, vecino de Vilafranca, en atención a cierta cantidad que debe a Antoni Florenç, vecino de Vilafranca, por razón de cereales, cede sus derechos contra el notario Sancho Sanz por 152 sueldos y el censo debido ratione dicti safranaris de quibus est obligatus in libro curie, así como contra Domingo Centelles por otros 88 sueldos y el censo debido ratione cuiusdam safranaris de quibus est obligatus in libro curie.

06/ 1396, octubre 15 (ANM, prot. 73). Ramón Blasco, vecino de Vilafranca, confiesa deber al herrero Joan Ivanyes 63 sueldos razón de un safranar que éste le vendió, sito en la tierra de Antoni Florenç, en término de Vilafranca, en la partida de Les Cingles, a pagar a san Miguel.

07/ 1400, noviembre 2 (ANM, prot. 115). Benet Vinaxa, vecino de Olocau, confesó deber a Guiamoneta viuda de Jaume Altafulla, 3 cahices de azafrán a entregar el próximo mes de mayo.

08/ 1410, abril 2 (ANM, prot. 150). En el contrato de Joan Estrader como munter e meseguer para guardar los cultivos del Vilafranca de los ciervos, corzos, cabras montesas, cerdos salvajes y otras bestias, por tiempo de 5 años, si indica en un ítem que debe guardar especialmente los safranars e pesolades e guareyts, si bien a continuación se indica que lo dit Johan no sia tengut d'esmenar les dites tales dels safranars, pesolades e guareyts, mes dels dits blats e altres coses segons en les cartes de la mesegueria és contengut.

09/ 1413, noviembre 25 (ANM, prot. 159). Domingo Doménech y su esposa María, vecinos de Cinctorres, donan el ajuar a su hijo Guillamó, compuesto por casa, cereal, moneda contante, cubas de vino y varias parcelas de tierra y viña. Se unen los cinco cahices de azafrán plantado, del millor que han. 
10/ 1415, noviembre 6 (ANM, prot. 120). Domingo Casanova, vecino de La Todolella y Aparici Blasco, vecino de La Mata, confesaron deber a Domingo Carbó, de La Mata, 276 sueldos 6 dineros precio de 11 libras y 3 cuartos de azafrán, a pagar en santa María de septiembre.

11/ 1416, mayo 17 (ANM, prot. 121). Joan Espinosa y Oria, vecinos de La Cuba, confesaron deber a Nicolau Trullench, vecino de Cantavieja, 22 sueldos precio de 4 fanegas de trigo, a pagar hasta santa María de septiembre. Como garantía del pago ofrecen lo safrà e l'ort.

12/ 1416, diciembre 3 (ANM, prot. 121). Pere Batle, vecino de La Cuba vende a Bertomeu Vilaplana, vecino de Mirambel, hun troz de safrà que yo tinch e posseesch en lo terme de Mirambell, loch apellat al barranch de La Cuba, en la terra del senyor Castelan, que afronte ab lo barranch e ab safranar de Bernat d'Alp, por un precio de 24 florines.

13/ 1417, diciembre 5 (ANM, prot. 122). Nadal Sola vecino de La Mata confiesa deber a Domingo Blasco, cordelero de La Mata, una libra y media de azafrán, bo, bel e mercader, a entregar el día de san Martín.

14/ 1418, diciembre 16 (ANM, prot. 159). Antoni Moliner vecino de Cinctorres confiesa deber a Domingo Lestreri, vecino del mismo lugar, 22 sueldos 6 dineros precio del azafrán plantado que le ha vendido situado en Les Solanes de Cellumbres, a pagar el día de Todos Santos. Se canceló el 28 de octubre del año siguiente.

15/ 1418, diciembre 19 (ANM, prot. 159). Jaume Guardiola vecino de Cintorres confiesa deber a Mateu Albaro, del mismo lugar, 51 sueldos precio de 3 cahices de safrà en caboça, bo, bell e reebedor, a pagar el día de Todos Santos. Se canceló el 13 de noviembre de 1419.

16/ 1418, diciembre 30 (ANM, prot. 159). Domingo Salvador, vecino de Cintorres, confiesa deber a Antoni Moliner, vecino de dicho lugar, 91 sueldos precio de 2 cahices, 5 barcillas y 1 quartal de azafrán plantado que posee debajo la dehesa d'en Girona, a pagar hasta Todos Santos.

17/ 1419, enero 11 (ANM, prot. 65). Redactados los documentos en La Cuba, Jordán d'Alagó y su esposa Pascuala confesaron deber a Pere Miquel, vecino de Cantavieja, 2 cahices de trigo que les había prestado, a pagar hasta mayo. Como garantía del pago le ofrecen una suerte de tierra con azafrán sita en el Colet d'en Sabater, frente la viña de Simó Mir. A continuación, son Joan Espinosa y su esposa Oria quienes confiesan deberle otros 81 sueldos 6 dineros por préstamo, a pagar hasta mayo. Le ofrecen 
como garantía del pago el azafrán que tienen en la tierra d'en Vallés, en la masía de Durbán.

18/ 1419, octubre 25 (ANM, prot. 159). Partición de bienes muebles e inmuebles entre na Pascuala y sus hijos. Algunos se mantienen comunes, como la palla, los safranars e les sementeres, e la verema que ara pengen e són en les dites heretats.

19/ 1419, diciembre 28 (ANM, prot. 159). Domingo Salvador, vecino de Cintorres, confiesa deber a Guiamó Castellano, del mismo lugar, 174 sueldos precio de 3 cahices de cereal y otros 3 cahices de azafrán plantado que posee en el Collet d'en Sebastià, en su heredad, a pagar hasta Todos Santos.

20/ 1420, enero 2 (ANM, prot. 159). Domingo Albaro vecino de Cinctorres confiesa deber a Jaume Maçana, del mismo lugar, 86 sueldos precio de cereales y azafrán plantado, a pagar hasta Todos Santos. Se canceló el 12 de octubre del 1421.

21/ 1420, enero 17 (ANM, prot. 159). Pere Guardiola el menor y Guiamó Gisquerol, vecinos de Cinctorres, confiesan deber a Bertomeu Marçá, vecino de dicho lugar, 67 sueldos 6 dineros precio de azafrán plantado, a pagar en fiesta de Todos Santos.

22/ 1420, enero 25 (ANM, prot. 124). Nicolau Favara vecino de La Mata confiesa deber a Antoni Rocafort, de La Mata, 17 florines razón de mercadería de azafrán, a pagar en 15 días.

23/ 1420, febrero 24 (ANM, prot. 159). Pere Vilanova y Antoni Torrelles, vecinos de El Forcall, junto a Nicolau Guerrero vecino de Cinctorres, confiesan deber a Francesc Montlober, notario de Cinctorres, 112 sueldos 9 dineros precio de safrà en bri que le han comprado, a pagar en fiesta de santa María de agosto.

24/ 1420, mayo 29 (ANM, prot. 124). Arnau Jover, vecino de La Cuba, confesó deber a Domingo Carbó 70 sueldos por hun banquall de safrà, a pagar hasta san Miguel de septiembre.

25/ 1420, junio 10 (ANM, prot. 159). Pere Guardiola el menor y Domingo Salvador, vecinos de Cinctorres, confiesan deber a Domingo Calbo, vecino del mismo lugar, 32 sueldos precio de azafrán en caboça, a pagar hasta Carnestoltes.

26/ 1420, septiembre 5 (ANM, prot. 124). Nadal Sola confesó deber a Domingo Carbó vecino de la Mata, 70 sueldos per hun tros de safrà, a pagar en Navidades. 
27/ 1420, diciembre 15 (ANM, prot. 124). Bartomeu Vallés hijo de Bartomeu, y su esposa Francesca, venden a Ramón d'Alp 8 cahices de azafrán plantado que tienen en la tierra de Bernat Terça, en término de Olocau, en la partida de Les Lomes. También le venden 32 ovejas. Añaden además otros 2 cahices de azafrán plantado en la tierra de Joan de Vilanova en término de La Mata, así como una suerte de tierra franca con el azafrán allí plantado situada en término de La Mata en el lugar llamado La Loma. También le venden una viña en La Mata en el barranco de La Cova, todo en conjunto por 500 sueldos. A continuación, Bartomeu Vallés el padre, Pascuala y Joan de la Torre, le venden otros 8 cahices de azafrán plantado en la tierra de Joan de Vilanova, por 117 sueldos 6 dineros.

28/ 1421, enero 2 (ANM, prot. 159). Arnau Agulló vecino de Cinctorres confiesa deber a Jaume Guardiola, vecino del mismo lugar, 88 sueldos 6 dineros precio de azafrán plantado que Jaume posee en una tierra en la partida dels Fontanals, a pagar hasta Todos Santos.

29/ 1421, marzo 10 (ANM, prot. 159). Domingo Lestreri, vecino de Cintorres, alquiló a Domingo Agulló vecino del mismo lugar, una serie de tierras y casetas en la masada de Celumbres, por tiempo de 5 años y bajo ciertas condiciones. Entre ellas se hace mención a que queda para Lestreri una poqua persolada que ara y ha, ab I puntalet après per a persolar, roman al dit Lestreri per a plantar saffrà mentre tenir se vulle.

30/ 1421, agosto 25 (ANM, prot. 159). Arnau Agulló vecino de Cinctorres confiesa deber a Domingo Calbo, del mismo lugar, 22 sueldos 7 dineros precio de un trozo de azafrán plantado en una suerte de tierra en la Torre de Les Navalles que de él compró, mentre tenir se vulle franch de loguer, a pagar hasta Todos Santos.

31/ 1421, agosto 27 (ANM, prot. 64). Pere Çavall, notario habitante en La Mata, vende a Jaume García, vecino de Cantavieja, un safranar sito en término de Cantavieja, en la partida del Donatiu, por precio de 100 sueldos jaqueses, cantidad que se compromete a satisfecer en dos pagas.

32/ 1421, octubre 21 (ANM, prot. 159). Antoni Agulló vecino de Cinctorres confiesa deber a Arnau Agulló, del mismo lugar, 41 sueldos precio de un trozo plantado de azafrán que le ha comprado y que Arnau posee en la tierra de Domingo Calbo, en la Torre de Les Navalles, a pagar a san Miguel. Se canceló el 25 de noviembre de ese año. 
33/ 1422, diciembre 7 (ANM, prot. 159). Antoni Agulló vecino de Cinctorres, en paga de 50 sueldos de los 57 sueldos y 6 dineros que debe a Arnau Pallarés, del mismo lugar, le vende el azafrán plantado que posee en Los Tosçals, en un trozo de tierra que antaño era suyo, pero ahora es de Antoni Castellano. Se compromete a tenir e posseir lo dit safranar a tant de temps com ell lo y havie tenir, franchament sens loguer.

34/ 1425, enero 2 (ANM, prot. 160). Bernat Bilba, vecino del Forcall confiesa deber a Alfonso Sorolla, vecino de Cinctorres, 200 sueldos precio de azafrán en bri, a pagar hasta san Miguel.

35/ 1426, enero 3 (ANM, prot. 160). Nicolau Escrivà, vecino de Cinctorres, confiesa deber a Jaume Maçana, vecino del mismo lugar, 98 sueldos precio de lana y de safrà en bri, a pagar en dos mitades. Se canceló el 27 de octubre del 1427.

36/ 1426, marzo 19 (ANM, prot. 125). Antoni Coloma vecino de La Mata vende a Nicolau d'Alp tot lo meu saffrà lo qual jo tinch en la terra de Berthomeu Roquafort, precio de 5 florines.

37/ 1426, octubre 27 (ANM, prot. 160). Bernat Porta y Jaume Vilella, vecinos de Olocau, confiesan deber a Jaume Maçana, vecino de Cinctorres, 200 sueldos precio de safrà en bri, a pagar 80 sueldos en fiesta de san Joan, y el resto a santa María de agosto.

38/ 1427, enero 23 (ANM, prot. 125). Antoni Coloma vecino de la Mata vende a Ramón d'Alp tot lo meu saffrà que yo tinch en la terra de Pere Casanova, en la Solana, precio de 44 sueldos.

39/ 1427, febrero 10 (ANM, 160). Partición de bienes entre na Ferrera y sus hijos, en Cinctorres. Se mencionan los 3 cahices de azafrán plantado, más o menos, que están en una suerte de tierra en la partida Dels Fontanals, y que corresponden a los hijos.

40/ 1428, mayo 17 (ANM, prot. 160). Partición de bienes entre na Guiamona, viuda de Joan Galindo, vecino de Cinctorres, y su hijo Joan. Entre las numerosas parcelas, se menciona que romanen comuns e per partir lo saffranar que és en lo dit troç de terra del Colomer d'en Domènech, así como las sementeras que en esos momentos cuelgan en el resto de parcelas. La parcela con el azafrán se situa en término de Cinctorres, en el camino que va al Forcall.

41/ 1428, agosto 25 (ANM, prot. 186). Miquel Martí, vecino del Forcall confiesa deber a Pere Casanova, vecino de La Mata, 80 sueldos raó de dos 
caffiços de safrà plantat que de vos comprí, a pagar 15 días después de la próxima fiesta de Todos Santos.

42/ 1429, marzo 23 (ANM, prot. 187). Pere Batle, habitante en La Cuba, confiesa deber a Joan Tallada, habitante en La Mata, 2 libras y 3 onzas de safrà sech por razón de préstamo, a entregar en Todos Santos. Se canceló el 26 de noviembre de ese año.

43/ 1429, mayo 14 (ANM, prot. 161). Bartomeu Ferrer, vecino de Ortells, confiesa deber a Alfonso Soriano, vecino de Cinctorres, 250 sueldos precio de safrà en bri que le ha comprado, a pagar a Santa María de Agosto.

44/ 1429, diciembre 15 (ANM, prot. 187). Antoni Anyó, vecino de Olocau, confiesa deber a Joan Tallada, habitante en La Mata, 105 sueldos restantes del precio de azafrán que le compró, a pagar hasta santa María de agosto.

45/ 1434, octubre 4 (ANM, prot. 165). Jaume Rosinyol, sastre, y su esposa Joaneta, vecinos de Morella, venden a Pasqual Molinos un troç de terra e safrà tot ensemps, sito en Cinctorres, en la partida de debajo del Peiró de debajo de la villa, frente el camino que va a Les Nogueretes y tierras de Domingo Lestreri y de Antoni Castellano, precio de 310 sueldos.

46/ 1436, febrero 26 (ANM, prot. 162). Bartomeu Vives y su esposa Calatayú Aguilar, vecinos del Portell, confesaron deber a Gabriel Tárrega, notario de Cinctorres, 123 sueldos restantes del precio de forment e safrà en bri que le compraron, a pagar hasta fiesta del Corpus.

47/ 1438, febrero 13 (ANM, prot. 242). Pere Baylle (o Batle), vecino de La Cuba, confiesa deber a Paulo Pedro, vecino de Morella, 2 cahices y medio de cabota de safrà, bo, bel, redon e rebedor a mesura del regne de València, a pagar hasta el día de santa María de agosto.

48/ 1439, febrero 1 (ANM, prot. 242). En el testamento de Antoneta, esposa de Miquel Carbó el menor, entre su legado se hace mención a que su hijo Antoni recibirá, antes de la partición, 4 cahices de cabota de safrà plantat a conocida de los albaceas.

49/ 1439, febrero 12 (ANM, prot. 242). En la venta de bienes de los hijos de Bernat Alcalá y de su esposa se consignan los 18 sueldos que pagó el notario de La Mata Domingo Gorch por quatre faneques de safrà comú dels dits pubills.

50/ 1439, septiembre 10 (ANM, prot. 242). Ramón Rocafort, en calidad de tío, tutor y curador de los bienes, hijos y herederos de su hermano difunto Barto- 
meu Rocafort, vecino de La Mata, pide inventario de bienes que tocan a los pubiles. Entre los animales, ropas, armas, etc... se menciona que recayó a parte de los pubiles 5 libras de azafrán seco, así como 6 cahices de azafrán plantado poco más o menos. A continuación, se realiza la venta de bienes para sufragar los gastos, indicándose que se pagó por rasclar el azafrán, 20 dineros. A los labradores o raedors del azafrán, 9 dineros. A continuación, se consigna el gasto a los esbrinadors, a saber por desbriznar el azafrán, primero pagó a la mujer del sastre Pascual Roselló (ítem tachado). A continuación, pagó en esbrinar el azafrán que eran 25 libras, a los desbriznadores en conjunto, 25 sueldos. Les pagó también un cesto de cebollas por 5 dineros, así como una libra y media de queso por 6 dineros, tres cántaros de vino por 6 sueldos, trigo para comer en cantidad de 3 barcillas, así como un sueldo por 2 libras de candelas de sebo para dezbrinar. También incorpora un ítem o anotación por colocar todo el mencionado azafrán, a coneguda. Finalmente consigna que vendió el azafrán seco de los pubiles, que alcanzó un peso global de 5 libras 1 onza y 1 cuarto, por un total de 160 sueldos 10 dineros.

51/ 1440, febrero 7 (ANM, prot. 243). En la división de bienes del difunto Antoni Osset, le corresponde a su hija Guiamoneta casada con Pere Prunyonosa, vecinos de Olocau, los béns mobles e safranars.

52/ 1440, abril 24 (ANM, prot. 243). En el codicilo al testamento de Guiamó Rosselló, deja éste a su esposa María la mitad de una casa, un mantón, y una viña que ella aportó, así como tot lo safrà que nos tenim e tendrem en aquell temps que yo defaliré. El testamento se publicó el 9 de agosto de ese mismo año.

53/ 1441, noviembre 30 (ANM, prot. 249). Domingo Gassulla, vecino del Portell confesó deber a Antoni Castellano, vecino de Cinctorres, 197 sueldos 6 dineros precio de azafrán a pagar hasta Navidad. Se canceló el 31 de diciembre de dicho año.

54/ 1443, octubre 25 (ANM, prot. 244). Guillem Cerdá, presbítero vicario perpétuo de La Mata, vende a Paulo Pedro, habitante en La Mata, 1 cahiz de cabota de safrà plantado este año, en la partida de la Punta d'en Vilanova, término de la Mata, en una suerte de tierra de (en blanco). Añade también el azafrán que tiene en la viña de Martí Remiro, sita en el Peiró de debajo de la villa, precio de 300 sueldos.

55/ 1444, junio 19 (ANM, prot. 244). Nicolau Escuriola y su esposa Beatriu, habitantes en La Mata, venden a Guillem Cerdá, presbítero vicario perpé- 
tuo de La Mata, 2 cahices 9 barcillas de azafrán plantado en un trozo de tierra o viña que confronta con otras viñas, precio de 110 sueldos. Después Cerdá, con consentimiento del matrimonio, reconoce deber dicha cantidad a Bartomeu Blancafort, notario del Forcall, cantidad que el matrimonio le adeudaba precio de una mula de pelo moreno.

56/ 1444, agosto 3 (ANM, prot. 244). Martí Remiro habitante en La Mata vende a Guillem Cerdá, presbítero vicario perpétuo de La Mata, un cahiz de azafrán plantado que él tiene en la viña o tierra de Miquel Carbó, en la partida de la Costa de na Bernada, frente el camino viejo, la cuesta y camino que va a Cinctorres, afrontado con otras viñas, por precio de 30 sueldos.

57/ 1444, diciembre 24 (ANM, prot. 265). Ramón Aguilar, habitante en Les Alberedes en término de Portell, confesó deber a Domingo Martí, rector de la iglesia del Portell, 220 sueldos precio de safrà en bri, a pagar hasta santa María de agosto. Se canceló el 1 de octubre de 1448.

58/ 1445, noviembre 17 (ANM, prot. 244). Berenguer Capeyra vecino de Mirambel dona a su esposa Bartomeua una serie de bienes muebles, cubas, casas y tierras. Entre ellas se menciona una viña cerca del lugar de Mirambel con el azafrán que en ella está plantado.

59/ 1446, enero 21 (ANM, prot. 244). Joan Gil confiesa deber a Antoni Besaldú, vecino de Nules (en la Plana de Castelló), presente, 3 cahices de cabota de safrà a pagar el día de santa María de agosto.

60/ 1451, agosto? (ANM, prot. 245). Antoni Romeu habitante en La Mata vende a Joan Marmaneu, vecino de La Mata, todo el azafrán que tiene en el puerto de la Todolella, en una suerte de tierra de mosén Jaume d'Urries que ahora posee Antoni Bovill, así como una cuba de vino de 30 cántaros, todo por precio de 2 cahices y 4 barcillas de forment.

61/ 1452, febrero 8 (ANM, prot. 245). Pere Piquer vecino de La Todolella y Martí Remiro, habitante en La Mata, confiesan deber a Pere Cabanes, mercader vecino de Morella, 80 sueldos razón de cereal, a pagar hasta santa María de agosto. Como fiador principal ofrecen a Joan Bellvís. Se añade que Remiro ofrece como garantía a Bellvís cuatro cahices de azafrán plantado que él tiene en el Salt de Saranyana.

62/ 1452, junio 28 (ANM, prot. 196). Arnau d'Alp y su esposa Gabriela habitantes en La Mata, venden a Ramón Çavall, notario vecino de Cantavieja, huna sort de terra e vinya ab lo safrà plantat que en aquella és, sita en la 
Mata en la partida de la Mesquita. Unen otras dos sorts de tierra en Olocau, precio conjunto de 300 sueldos.

63/ 1453, octubre 26 (ANM, prot. 246). Pere Agulló y su esposa Francisca venden a Joan Marmaneu, una sort de terra e vinya e safranar e lo sementer, que afronta con otras parcelas y con el río. Añaden otra suerte de tierra en la partida de la Hortolana, en La Mata, con la sementera que allí hay. No indican precio.

64/ 1454, agosto 27 (ANM, prot. 246). Joan Avinyó habitante en La Mata confiesa deber a Guiamó Marmaneu, vecino de Cantavieja, 77 sueldos por el azafrán plantado, a pagar mitad en san Miguel y mitad en Pascua Florida.

65/ 1455, febrero 28 (ANM, prot. 266). Joan Yago, herrero habitante en Fortanete, cede a Pascual Escuder, vecino de Mosqueruela para resarcirlo en parte de 290 sueldos que le adeuda, dos cahizadas y media de azafrán plantado que Yago posee en un trozo de tierra sito en Portell, en la partida de la Serra.

66/ 1455, abril 24 (ANM, prot. 197). Nicolau Royo, habitante en La Mata cede 8 cahices de azafrán plantado, a (en blanco) para resarcirle por razón de 2 paños de burel, permitiendo que pueda vender dicho azafrán.

67/ 1455, abril 25 (ANM, prot. 266). Joan Blasco y su esposa Dolceta, vecinos de Portell confesaron deber a Joan Pastor, masovero habitante en la Torre de Joan Martí, en término de Cantavieja, 3 cahices y 1 fanega de safrà en cabota, en calidad de permuta por un rocín de pelo negro que les ha dado Pastor. El azafrán lo entregarán en Portell el día de santa María de agosto. Se canceló el 24 de agosto de 1455.

68/ 1455, diciembre 17 (ANM, prot. 197). Joan Aznar y su esposa Francesca, vecinos de Olocau, venden al notario de dicho lugar Francesc Castellano 7 cahices de azafrán plantado en una tierra sita en término de Olocau, así como lo sementer en otras tres parcelas, precio global de 700 sueldos.

69/ 1460, marzo 17 (ANM, prot. 198). Jaume Yagüe, vecino de la Iglesuela reconoce deber a Sancho Altabas, vecino de Cantavieja, 150 sueldos jaqueses precio de un bóvido de pelo rojizo y cierta cantidad de cebada, a pagar hasta Todos Santos. Como garantía de pago obliga un safranar que yo tinch en lo terme de la Esglesiola, en la partida de les Fontanelles, que afronte $a b$ terra de vos dit Sancho Altabas de dues parts, e ab camí públich e ab heretat de Sancta Maria del Cit. Acto hecho en la Mata de Morella. 
70/ 1462, febrero 15 (ANM, prot. 247). Joan Aznar el mayor, vecino de Olocau, confesó deber cierta cantidad a Joan Catalá, vecino de La Mata. Indica que le vendió un par de bóvidos, así como nueve libras de cabota de çafrà plantado en una suerte de tierra en la partida de la Condonyera, frente al barranco.

71/ 1462, marzo 2 (ANM, prot. 247). Testamento de Lorenç Monlober vecino Forcall, quien legó a su hijo una viña, una cuba de vino, unas casas y tres cahices de cabota de safrà.

72/ 1462, abril 23 (ANM, prot. 198). Antoni Gralla y su esposa Úrsula, habitantes en La Mata, confesaron deber a Joan Mançana, vecino de dicho lugar, 123 sueldos 4 dineros por razón de safrà plantat que le compraron, a pagar hasta Navidad.

73/ 1462, noviembre 7 (ANM, prot. 247). Miquel Sorribes, vecino de La Cuba vendió a Joan Loça, vecino de La Mata, 4 cahices de cabota de safrà plantat en huna sort de terra mia, francha, sita en el plano del secano, precio de 100 sueldos.

74/ 1482, abril 18 (ANM, prot. 286). Francesc Joan vecino de Forcall confiesa deber a Pere Mormeneu, 9 cahices de bota de çafrà per rahó de un tros de safranar que le ha comprado en una heredad que Mormeneu posee en la partida de Les Solanes plantado del primer año.

75/ 1488, octubre 4 (ANM, prot. 279). Gabriel Scuriola, de La Mata, es condenado en un arbitraje a satisfacer un pago de 50 sueldos, que puede ser sustituido por una libra de azafrán seco junto con un cahiz de cereal.

76/ 1502, abril 10 (ANM, prot. 293). Bernat Vilanova, habitante en La Mata, arrienda a Francisco Batle vecino de Palanques una masía que está parte en término de Luco y parte en término de Forcall, a 6 cosechas y censo de 3 cahices de cereal, pudiendo Vilanova mantener por un año el azafrán que ara y tinc.

\section{Conclusiones}

Ofrecemos al investigador un global de 76 regestos documentales relativos al cultivo y comercio del azafrán en un ámbito geográfico interior, de carácter montañoso, como es la zona de Gúdar-Maestrazgo, que pone en contacto dos áreas históricas y administrativas diferenciadas, pero vecinas y en continua ósmosis social, económica y cultural durante la Edad Media. A su vez, reivin- 
dicamos el valor del azafrán como patrimonio cultural e histórico que marcó, y ha marcado hasta no hace muchos años, parte del saber agrario de las gentes que habitan en la vertiente turolense de la zona ahora estudiada. Además, estas líneas permiten completar un poco más el puzle relativo a las zonas productoras (y/o exportadoras) del azafrán dentro del ámbito de los territorios de la antigua Corona de Aragón. Dicho cultivo y comercio a nivel local y comarcal queda atestiguado, al menos y según la documentación disponible, entre 1392 y 1502. Con todo, reconocemos la dificultad de vislumbrar el impacto que este cultivo pudo tener en la economía doméstica familiar, así como también los posibles cauces para una ulterior comercialización del producto más allá del propio ámbito local o comarcal.

\section{Referencias bibliográficas}

APARICI MARTí, Joaquín (2010), «Ósmosis socio-económica entre territorios limítrofes. La permeabilidad del Maestrazgo turolense y castellonense en los siglos XIV y XV». Studium, Revista de Humanidades, núm. 16, pp. 39-56.

CASADO Novas, Iván (2014), Mercaderes alemanes en la Cataluña de la primera mitad del cuatrocientos: el comercio del azafrán en Barcelona según el «Dret dels Alemanys i saboyans» (1425-1445). Trabajo de Fin de Máster. Barcelona, Universidad de Barcelona.

CASAdo Novas, Iván (2014-2015), «Las exportaciones de azafrán en la Barcelona del cuatrocientos: la intervención de los operadores alemanes según el Dret dels alemanys i saboyans (1425-1445)», Acta Historica et Archaeologica, Mediaevalia, 32: 579-618.

Diago, Máximo (2002), «Los mercaderes alemanes en los reinos hispanos durante los siglos bajomedievales: actividad de las grandes compañías en la Corona de Aragón», España y el Sacro Imperio. Procesos de cambios, influencias y acciones recíprocas en la época de la europeización (ss. XI-XIII), Valladolid: 299-328.

Galera i Pedrosa, Andreu (2015), «Senyoriu, sal i safrà. Economia regional i oligarquies urbanes a la vila i comtat de Cardona a l'alba del 1400». En María Teresa Ferrer i Mallol, ed., Martí l'Humà: el darrer rei de la dinastia de Barcelona (13961410): l'Interregne i el Compromís de Casp. Barcelona, Institut d'Estudis Catalans: 533-564.

Guiral HadziIOSSIF, Jacqueline (1989), Valencia, puerto mediterráneo en el siglo xv. Valencia, Alfons el Magnànim.

López Elum, Pedro (1975), «El comercio de exportación e importación de los mercaderes venecianos con el reino de Valencia durante el año 1440». En Juan Reglá, ed., Estudios sobre el Reino de Valencia. Madrid, CSIC: 117-165. 
MARTínez GARCía, Sergio (2012), «Producción y mercado de azafrán al sur de Aragón durante el siglo xv: el ejemplo de Muniesa, una aldea del Común de Huesa». En Carlos Laliena Corbera y Mario Lafuente Gómez, coords., Una economía integrada, comercio, instituciones y mercados en Aragón. Zaragoza, Grupo Cema: 319344.

Mira Jódar, Antonio José (2005), «Circuitos marítimos de intercambio y comandas mercantiles en Valencia durante la primera mitad del siglo XIV». En La Mediterrània de la Corona d'Aragó, segles XIII-XVI. VII centenari de la Sentencia arbitral de Torrellas, 1304-2004. (XVIII Congrés d'Història de la Corona d'Aragó). València, Universitat de València. Vol 1: 1369-1394.

Navarro Espinach, Germán (2008), Cuentas del concejo de Mirambel (1472-1489). Zaragoza, Departamento de Historia Medieval, Universidad de Zaragoza-Instituto de Estudios Turolenses.

NAVArro EsPinach, Germán y Joaquín Aparici Martí (2008), «Villarluengo, un lugar de la bailía de Cantavieja en el siglo xv», Aragón en la Edad Media, 20 (Homenaje a la prof. M. D. Cabanes Pecourt): 543-558.

Petino, Antonio (1951), Lo zafferano nell'economia del medioevo. Catania, Università. (Serie: Studi di Economia e Statistica, 1).

Polonio Luque, Gloria (2012), Exportación e importación en y desde el Mediterráneo en la Baja Edad Media. Mercaderes, mercancías y rutas comerciales (1349-1450). Tesis en red. Barcelona, Universitat de Barcelona.

RAfat I Selga, Francesc (1993), «Manresa en l'exportació de safrà durant el segle XIV». En Francesc Rafat, Masos, safrà, occitans i pesta negra: estudis d'història de la Catalunya central. Manresa, Centre d'Estudis del Bagés: 270-279.

Rubio Terrado, Pascual (1997), El azafrán y la comarca del Jiloca. Calamocha, Centro de Estudios del Jiloca.

Rubio Terrado, Pascual (2007), «El azafrán. Aspectos socioeconómicos y culturales». Studium. Revista de Humanidades, 13: 199-228.

SAlicrú i Lluch, Roser (1995), El tràfic de mercaderies a Barcelona segons els comptes de la lleuda de Mediona (febrer 1434). Barcelona, CSIC.

Schulte, Aloys (1923), Geschichte der Grossen Ravensburger Handelsgesellschaft (1380-1530). Stuttgart und Berlin, Deutsche Verlags-Anstalt. Disponible en red.

Sesma Muñoz, José Ángel (2005), Huesca, ciudad mercado de ámbito internacional en la Baja Edad Media según los registros de su aduana. Zaragoza, Departamento de Historia Medieval de la Universidad de Zaragoza.

Verdés I Pijuan, Pere (2001), «Una espècia autòctona: el comerç del safrà a Catalunya durant el segle XV», Anuario de Estudios Medievales, 31/2: 757-785.

Verdés i PiJuAn, Pere (2008), «La fiscalidad sobre el azafrán. Una «cuestión de estado» en la Cataluña del siglo XV». En Rafael Vallejo Pousada y Antoni Furió, coords, Los tributos de la tierra: fiscalidad y agricultura en España (ss. XII-XX). Valencia, Universitat de València, Servei de Publicacions: 422-444. 
Joaquín Aparici Martí

Villanueva Morte, Concepción (2007), Hacienda y fiscalidad en el Alto Palancia durante el siglo XV: estrategias e impuestos comerciales en una comarca fronteri$z a$. Segorbe, Ayuntamiento de Segorbe. 